\title{
Advanced Cognitive Behavioral Therapy for Insomnia (CBT-I) Based on Acceptance and Commitment Therapy Compared With CBT-I: A Pilot Study
}

\author{
Seonyeop Kim ${ }^{1}$, Yoon Jung Shin ${ }^{2}$, Bomi Park ${ }^{1}$, Sunyoung Park ${ }^{3}$, Jung-Won Shin ${ }^{2}$ \\ ${ }^{1}$ Graduate School of Medicine, CHA University, Seongnam, \\ ${ }^{2}$ Department of Neurology, Memory Center, CHA Bundang Medical Center, CHA University, Seongnam, \\ ${ }^{3}$ Graduate School of Clinical Counselling Psychology, CHA University, Seongnam, Korea
}

\author{
수용전념치료에 기반한 심화된 불면증 인지행동치료와 불면증 인지행동치료 비교의 예비연구 \\ 김선엽1, 신윤정 ${ }^{2}$, 박보미 ${ }^{1}$, 박선영 ${ }^{3}$, 신정원 ${ }^{2}$ \\ ${ }^{1}$ 차의과학대학교 일반대학원 의학과, ${ }^{2}$ 차의과학대학교 분당차병원 기억력센터 신경과, ${ }^{3}$ 차의과학대학교 임상상담심리대학원
}

$\begin{array}{ll}\text { Received } & \text { February 3, } 2021 \\ \text { Revised } & \text { March 22, 2021 } \\ \text { Accepted } & \text { June 24, 2021 }\end{array}$

Address for correspondence Jung-Won Shin, MD, PhD

Department of Neurology, Memory Center,

CHA Bundang Medical Center,

CHA University,

59 Yatap-ro, Bundang-gu,

Seongnam 13496, Korea

Tel: +82-31-780-5058

Fax: +82-31-780-5198

E-mail: limitsum@gmail.com

\begin{abstract}
Objectives: Cognitive behavioral therapy for insomnia (CBT-I) is the first line treatment for insomnia. However, many patients remain with sleep disturbances even after undergoing CBT-I, and those with short sleep durations have shown fewer gains. Acceptance and commitment therapy (ACT) is one of the third wave of behavioral therapies, and it is useful in helping patients get flexibility of mind. Therefore, we incorporated its components into CBT-I, came up with an advanced CBT-I program that involves cognitive behavior therapy based on ACT, and examined its efficacy in comparison to that of CBT-I. Methods: Patients with chronic primary insomnia were recruited at the memory center of CHA University Hospital from June to August 2020. To examine the efficacy of advanced CBT-I compared to that of CBT-I, the patients $(n=16)$ were assigned to two groups (CBT-I: $n=6$; advanced CBT-I: $n=10)$. The patients in each group were treated for 4 weeks (8 sessions). The quality of sleep, severity of insomnia, sleepiness, depression, anxiety, acceptance, efforts to sleep, and dysfunctional beliefs concerning sleep were assessed with self-report questionnaires. Results: The severity of insomnia, quality of sleep, depression, anxiety, acceptance, efforts to sleep, and dysfunctional beliefs concerning sleep improved after both CBT-I and advanced CBT-I treatment. Conclusions: This study examined the efficacy of advanced CBT-I in improving the severity of insomnia, sleep quality, and other symptoms related to sleep. The results suggest that components of ACT were useful for insomnia.

J Sleep Med 2021;18(2):78-87
\end{abstract}

\section{서 론}

수면은 인간의 기본적인 활동으로 신체기능의 회복과 개 인의 안녕, 삶의 질에 긍정적인 영향을 미친다. ${ }^{1}$ 그러나 하루 평균 6시간 이하의 짧은 수면은 고혈압, 심혈관 질환과 당뇨 병, 비만의 위험률을 증가시키고 ${ }^{2}$ 우울, 인지기능 및 삶의 질 을 저하시킨다. ${ }^{2,3}$ 불면증의 발생에는 다양한 생물 심리 사회

This is an Open Access article distributed under the terms of the Creative Commons Attribution Non-Commercial License (https://creativecommons.org/licenses/by-nc/4.0) which permits unrestricted non-commercial use, distribution, and reproduction in any medium, provided the original work is properly cited.
적인 영역, 심리적, 인지적 요인과 관련이 있는데, ${ }^{4}$ 특히 인지 적인 요인이 불면증 악화에 핵심적인 요인으로 간주되고 있 다. ${ }^{5}$ 지속요인으로는 심리 및 행동적 요인이 있으며, 이로 인 해 불면증이 만성화된다. ${ }^{6}$ 불면증 치료에는 만성적인 불면증 으로 진행하게 하는 지속요인을 다루는 적절한 치료적 개입 이 필요하고, 치료가 종료된 후에도 재발을 억제할 수 있게 하는 것이 매우 중요하다.

불면증을 위한 인지행동치료(cognitive behavior therapy for insomnia, CBT-I)는 수면에 부정적인 영향을 미치는 행 동과 인지를 교정하는 비약물 치료로서, 미국과 유럽 등에서 
첫 번째 치료법(the first-line treatment)으로 권장되고 있다. $\mathrm{CBT}-\mathrm{I}$ 는 4회기에서 8회기의 단기로 구성되며, 자극조절과 수면제한 등의 방법을 통해 불면증을 지속시키는 인지적인 요인들을 제거하여 수면을 향상시키는 것을 목적으로 한다. 8 지금까지 약물 치료의 대안적 치료로서 CBT-I는 충분히 그 효과와 필요성이 입증되어왔다. 그러나 약 $40 \%$ 에 이르는 환 자가 CBT-I에서 낮은 효과를 보였는데, ${ }^{9}$ 이는 CBT-I가 적 합하지 않았던 불면증 환자가 그 대상이었거나 치료 프로그 램에 끝까지 따라오지 못한 결과일 가능성을 생각해볼 수 있다. 이처럼 CBT-I에 적합하지 않거나 치료 프로그램에서 중도 탈락하여 낮은 효과를 보이는 원인에 대하여 지금까지 밝혀진 변인들로는 우울증의 심각성, ${ }^{10}$ 공존 질환, ${ }^{11}$ 장기간의 수면제한과 자극조절 시행의 어려움 ${ }^{12}$ 등이 있다.

수면은 조절할 수 없는 불수의적인 과정으로 불면증에 대 한 노력과 통제는 역설적으로 수면에 실패하고 반복되는 만 성 불면증의 악순환을 유발한다. ${ }^{13}$ 그러나 전통적인 CBT-I는 불면증을 지속시키는 인지와 행동의 변화를 통한 증상 감소 만을 주로 다루므로 낮은 효과 및 순응도의 악순환을 지속시 킬 수 있다. 따라서 수면장애의 증상에 대해 좀 더 수용적인 태도를 취하도록 환자를 교육하는 것이 더 효과적일 수 있 겠다.

이처럼 CBT-I의 한계점을 보완하기 위해 인지행동치료의 제3의 물결에서는 마음챙김 기반 치료를 시작으로 많은 연 구가 이루어져 왔다. ${ }^{14}$ 기존의 인지행동치료가 형태에 초점 을 맞추어 비합리적인 사고와 행동의 수정에 중점을 두었다 면, 제 3 세대 인지행동치료는 기능에 초점을 맞추어 사건과의 관계를 바꾸기 위해 마음챙김, 수용 및 인지적 탈융합과 같은 개념을 사용한다. ${ }^{15}$ 불면증을 위한 마음챙김 기반 치료는 마 음챙김 훈련을 통해 비판단적으로 현재에 머무르게 함으로 써 생각과 감정들을 바꾸는 대신 이에 대한 알아차림을 증가 시키고 관찰할 수 있게 하는 새로운 메타인지적 과정을 획득 하게 하여 수면에 대한 역기능적인 신념과 기대 및 욕구를 감소시켜 각성을 낮추는 데 큰 효과를 보인다. ${ }^{16}$

인지행동치료의 제 3 의 물결 중 하나인 acceptance and commitment therapy (ACT) 또한 증상의 통제나 감소에 초 점을 두는 전통적인 $\mathrm{CBT}$ 와 달리 수용, 인지적 탈융합, 현재에 머무르기, 맥락으로서의 자기, 가치와 전념행동의 6가지 핵 심과정들을 통해 심리적 유연성의 증가를 목표로 한다. $\mathrm{ACT}$ 에서는 내적 경험을 통제하거나 바꾸려는 시도인 회피가 역 설적으로 더욱 강렬한 경험을 불러일으킨다고 주장하며 이 에 대한 대안으로 기꺼이 경험하기를 권유한다. 이러한 과정 은 불면증에 대한 단기적인 불안감과 신체감각의 불편감을 기꺼이 경험하게 함으로써 불면증의 악순환의 고리를 끊고
치료 효과를 잠재적으로 향상시킬 수 있다. ${ }^{17}$ 또한 $\mathrm{ACT}$ 는 가 치를 명료화하고 이에 따른 전념행동을 증가시키도록 하는 행동활성화의 과정을 포함한다. 이를 통해 질병의 증상에 초 점을 두기보다는 삶에 집중하고 가치에 따른 행동을 활성화 하도록 하여 불면증을 경험하는 환자들의 낮 일상에 의미 있 는 활동들을 증가하게 할 수 있다. ${ }^{18}$ Zakiei와 Khazaie ${ }^{19}$ 에 따 르면 ACT는 만성 불면증 환자의 수면의 질을 향상시켰으며 그 효과는 치료 후 3 개월까지 안정적으로 지속되는 것으로 나타났다. 또한 ACT의 선행연구에서는 6개월 후까지도 불면 증의 치료효과가 안정적으로 유지되었으며, 환자 스스로가 자신의 가치를 찾고 이를 위한 전념행동을 통해 삶의 질이 향상됨을 살펴볼 수 있었다. ${ }^{20}$

따라서 본 연구는 기존의 CBT-I가 가지고 있는 효과적인 변인들과 더불어 기존의 인지행동치료를 보완할 수 있는 제 3 의 물결 중 하나인 $\mathrm{ACT}$ 의 요소들을 첨가한 프로그램을 시 도해보고자 하는 가설검증의 예비연구이다. 이를 통해 프로 그램의 효과를 비교하여 가능성을 살펴보고자 한다.

\section{방 법}

\section{연구 대상}

본 연구의 대상자는 International Classification of Sleep Disorders-3 (ICSD-3)의 만성 불면증 진단기준에 부합한 ${ }^{21}$ 20세 이상의 성인을 대상으로 수행하였으며, 연구 참가자는 온라인과 오프라인 홍보 게시물 또는 병원 신경과 외래진료 를 통해 2020년 6월부터 8월까지 모집되었다. 연구 참여기준 은 구조화된 설문지 및 신경과 전문의에 의해 대면으로 인터 뷰를 진행한 후 만성 불면증으로 진단된 사람들을 대상으로 하였다. 연구 참여일로부터 4주 이내 정신과적 질환으로 진 단을 받거나, 정신과적 약물을 복용하고 있거나 복용했던 대 상자는 연구 참여에서 제외되었다. 연구 참여탈락은 회기를 완료하지 못하거나 사전-사후 설문지를 마치지 않은 경우 중 도탈락으로 정의하였으며, 연구 결과 분석에서 중도 탈락자 의 데이터는 제외하였다. 본 연구는 분당차병원 생명윤리위 원회의 심의를 거쳐 시행되었다(IRB No. 2020-06-028-001).

\section{측정 도구}

\section{피츠버그 수면의 질(Pittsburgh Sleep Quality Index, PSQI)}

주관적인 수면의 질을 측정하기 위해 Buysse 등2이 개발 한 피츠버그 수면의 질 척도를 사용하였다. 한 달 동안 잠자 리에 든 시간과 아침에 일어난 시간, 실제로 잔 시간, 잠드는 
데 걸린 시간의 항목들을 통해 수면잠복기, 수면효율, 총 수 면시간을 계산하였고 7개 영역으로 구성된 점수를 총합하여 수면의 질을 계산하였다. 점수가 높을수록 수면의 질이 낮음 을 의미한다.

불면증 심각도 척도(Insomnia Severity Index, ISI) 불면증 심각도를 측정하기 위해 Cho 등 ${ }^{23}$ 이 번안한 불면증 심각도 척도를 사용하였다. 수면의 만족, 주간기능의 손상, 불면으로 인한 고통 등의 항목을 측정하고, 총 7문항으로 구 성되어 있다. 점수가 높을수록 불면증의 심각도가 높음을 의 미하며 0-7점은 임상적 불면증 없음, 8-14점은 가벼운 수준 의 임상적 불면증, $15-21$ 점은 중등도 불면증, 22-28점은 중 증의 불면증으로 분류한다. ${ }^{24}$

\section{엡워스 졸림 척도(Epworth Sleepiness Scale, ESS)}

주간 졸음을 측정하기 위해 엡워스 졸림 척도 ${ }^{25}$ 를 사용하였 다. 졸음을 초래할 수 있는 8가지 상황을 설정하고, 각 상황에 따른 졸음의 정도를 4단계로 선택할 수 있게 구성되어 있다. 총 문항 합산 점수가 높을수록 주간 졸음의 정도가 심한 것을 의미한다.

주요 우울장애 척도(Patient Health Questionnaire-9, PHQ-9)

우울을 평가하기 위해 Han 등히 임상에서 우울증 선별 도구로 활용하기 위해 번안한 한국어판 PHQ-9를 사용하였 다. 지난 2 주간의 우울감, 수면의 변화, 식욕의 변화, 집중력, 자살사고 등의 항목을 통하여 우울증을 측정하며, 점수가 높 을수록 우울증의 심각도가 높다는 것을 의미한다.

\section{범불안 증상 척도(Generalized Anxiety Disorder-7, $\mathrm{GAD}-7)$}

범불안장애의 선별과 증상의 심각도를 평정하기 위해 Spitzer 등 ${ }^{27}$ 이 개발한 범불안 증상 척도를 사용하였다. 총 7 문항으로 구성되어 있으며, 점수가 높을수록 불안이 높다는 것을 의미한다.

\section{수용 행동 질문지(Acceptance and Action}

Questionnaire-II, AAQ-II)

자신의 가치와 목적에 부합하는 방식으로 행동하면서 생 각이나 느낌을 기꺼이 수용하는 정도를 측정하는 척도이다. $\mathrm{HeO}$ 등 ${ }^{28}$ 이 번안한 척도를 사용하였다. 총 10 문항으로 구성 되어 있으며, 10-70점으로 점수가 높을수록 수용을 많이 하 고, 경험 회피를 덜 하는 것을 의미한다.
한국판 글라스고 수면 노력 척도(Korean Glasgow Sleep Effort Sale, K-GSES)

잠을 자기 위한 노력 및 통제를 평가하기 위해 Kim 등 ${ }^{29}$ 이 번안한 한국판 글라스고 수면 노력 척도를 사용하였다. 총 7 문항으로 구성되어 있으며, 점수가 높을수록 수면을 통제하 기 위한 노력을 많이 한다는 것을 의미한다.

\section{수면에 대한 역기능적인 신념 및 태도 척도}

\section{(Dysfunctional Beliefs and Attitudes about Sleep}

\section{Scale-16, DABS-16)}

불면증 환자의 수면에 대한 잘못된 신념과 태도를 평가하 기 위하여 $\mathrm{Yu}$ 등 ${ }^{30}$ 이 번안한 수면에 대한 역기능적인 신념 및 태도 척도를 사용하였다. 불면증의 원인에 대한 오류, 불면 증의 결과에 대한 잘못된 귀인, 수면에 대한 비현실적 기대, 수면의 통제와 예측에 관한 지각의 감소, 수면을 촉진시키는 행위에 대한 잘못된 신념을 평가한다. 총 16 문항으로 구성되 어 있으며, 점수가 높을수록 수면에 대한 역기능적 신념과 태 도가 많다는 것을 의미한다.

\section{수면일기}

환자들은 치료 전 최소 7일 동안과 치료 종료 직후 최소 7일 동안 매일 수면일기를 작성하여 수면 습관을 확인하였다. 수 면일기를 통해 수면잠복기, 총 수면시간(잠자리에 누워 있는 총 시간-[수면잠복기+수면 중 각성시간]), 수면효율([총 수면 시간/잠자리에 누워 있는 총 시간 $\times 100)$ 을 계산하였다.

\section{프로그램 진행 절차}

모집된 연구 참여자들은 순차적으로 2020년 6월에는 CBT-I 프로그램에 배정되었고, 7월부터 8월까지의 참여자들은 $\mathrm{ACT}$ 에 기반을 둔 advanced CBT-I 프로그램에 배정되었다. 치 료에 들어가기 1 주 전 설문을 완료한 뒤 4주간의 불면증을 위한 개별요법 인지행동치료에 참여하였다. 본 연구는 인지 행동치료전문가 자격을 가진 임상심리전문가(SYP)의 수퍼 비전하에 임상상담심리학 박사과정 이상의 치료자(SYK, YJS)들이 진행하였다. 구조화된 프로토콜의 진행으로 치료 자 간의 효과 차이는 없었고, 참여자들은 치료자에 순차적으 로 배정되었다. 두 가지 프로그램 모두 주당 대면 치료 1 회, 온라인 기반 인지행동치료 1 회가 진행되어 4 주간 총 8 회기 가 진행되었다. 온라인 기반 인지행동치료는 병원 온라인 채 널을 개설하여 진행하였다. 온라인 채널은 메신저 앱을 통해 주 1 회 환자와 메신저로 상담하며, 환자의 상태 점검, 인지 행동치료 및 질의 응답과 치료 관련 자료와 영상을 전달할 수 있도록 활용되었다. 이후 4주의 불면증을 위한 인지행동 
치료가 끝나면 2주 뒤 사후 설문을 완료하고 모든 프로그램 참여가 마무리되었다.

\section{프로그램 구성}

본 연구의 프로그램은 불면증의 ACT 요소들을 기존 CBT-I 에 접목시킨 프로그램으로, 기존 불면증에서의 $\mathrm{ACT}$ 프로그 램들을 참고하여 재구성하였다. ${ }^{31-33} \mathrm{CBT}-\mathrm{I}$ 프로그램에는 수 면교육, 수면위생, 자극조절, 수면제한, 이완요법, 인지요법 등이 진행되었고, ACT에 기반한 advanced CBT-I 프로그램 에서는 수면위생, 수면에 대한 기꺼이 경험하기와 인지적 탈 융합, 현재에 머무르기, 삶의 가치 명료화와 이에 따른 전념 행동 활성화를 진행하였다. 기존의 CBT-I에서의 인지요법 이 수면에 대한 역기능적 생각의 변화와 행동수정을 중점적 으로 다루었다면, advanced CBT-I에서는 수면에 대한 생각 을 생각 그 자체로 바라보는 인지적 탈융합과 불면증상에 대
한 기꺼이 경험하기의 실천, 삶의 가치를 명료화하며 이를 실 천할 수 있는 전념행동을 중점적으로 다루었다. 이와 같은 내 용들을 불면증 인지행동 프로그램에 적용하여 8회기를 구성 하였다(Table 1).

\section{자료 분석}

본 연구의 자료 분석을 위해 SPSS 22.0 version (IBM Corp., Armonk, NY, USA)을 사용하였다. 먼저 연구 참여자들의 인 구통계학적 특성을 분석하기 위해 기술통계를 사용하였고 $\mathrm{t}$ 검증, 교차분석으로 분석하였다. 각 프로그램에 배정된 참가 자들의 사전 동질성 검증을 위해 independent t test와 Levene의 등분산을 실시하였다. 각 집단의 프로그램 효과 크기를 분석하기 위해 repeated measures ANOVA를 실시하였다.

Table 1. Protocol of CBT-I vs. advanced CBT-I

\begin{tabular}{|c|c|c|c|}
\hline & Session & CBT-I & Advanced CBT-I \\
\hline$\overline{1}$ & 1 week & $\begin{array}{l}\text { Explanation of CBT principles for insomnia (A-B-C model) } \\
\text { Education for sleep hygiene } \\
\text { Sleep education }\end{array}$ & $\begin{array}{l}\text { Explanation of ACT principles for insomnia } \\
\text { ( } 6 \text { components model) } \\
\text { Education for sleep hygiene } \\
\text { Dealing with sleep and stress (defusion) }\end{array}$ \\
\hline 2 & $\begin{array}{l}\text { Online } \\
\text { therapy }\end{array}$ & $\begin{array}{l}\text { Counselling (based on CBT) \& sending guidance } \\
\text { instructions of sleep hygiene }\end{array}$ & $\begin{array}{l}\text { Counselling (based on ACT) \& sending guidance } \\
\text { instructions of sleep hygiene }\end{array}$ \\
\hline 3 & 2 week & $\begin{array}{l}\text { Checking sleep diary } \\
\text { Sleep restriction \& stimulus control therapy } \\
\text { Progressive muscle relaxation training }\end{array}$ & $\begin{array}{l}\text { Checking sleep diary \& sleep restriction }{ }^{31} \\
\text { Avoidance of pain and acceptance in insomnia } \\
\text { (pain vs. suffering) } \\
\text { Creative hopelessness } \\
\text { Control is the problem in insomnia }\end{array}$ \\
\hline 4 & $\begin{array}{l}\text { Online } \\
\text { therapy }\end{array}$ & $\begin{array}{l}\text { Counselling \& sending instructions of stimulus } \\
\text { control \& sleep restriction in bed }\end{array}$ & $\begin{array}{l}\text { Counselling \& sending instructions of paradox } \\
\text { in controlling sleep }\end{array}$ \\
\hline 5 & 3 week & $\begin{array}{l}\text { Checking sleep diary } \\
\text { Review of sleep education \& sleep hygiene } \\
\text { \& sleep restriction } \\
\text { Cognitive therapy for insomnia } \\
\text { Find dysfunctional thoughts and behavior of insomnia }\end{array}$ & $\begin{array}{l}\text { Checking sleep diary } \\
\text { Review of sleep education \& sleep hygiene } \\
\text { \& sleep restriction }{ }^{31} \\
\text { Effects of being present \& self as context } \\
\text { Meditation of awakening here and now } \\
\text { Cognitive defusion for insomnia }\end{array}$ \\
\hline 6 & $\begin{array}{l}\text { Online } \\
\text { therapy }\end{array}$ & $\begin{array}{l}\text { Counselling of cognitive therapy for insomnia and } \\
\text { sending homework }\end{array}$ & $\begin{array}{l}\text { Counselling of being present relaxation } \\
\text { (staying here and now) }\end{array}$ \\
\hline 7 & 4 week & $\begin{array}{l}\text { Checking sleep diary } \\
\text { Sleep education \& sleep hygiene \& sleep restriction } \\
\text { Cognitive restructuring of dysfunctional thoughts and } \\
\text { behavior of insomnia } \\
\text { Plan a prevention of relapse }\end{array}$ & $\begin{array}{l}\text { Checking sleep diary } \\
\text { Looking at vs looking through thoughts } \\
\text { Write epitaph on paper and find the most } \\
\text { important values in life } \\
\text { Plan a value and committed action }\end{array}$ \\
\hline 8 & $\begin{array}{l}\text { Online } \\
\text { therapy }\end{array}$ & $\begin{array}{l}\text { Sending guidance and worksheet of cognitive therapy } \\
\text { for insomnia }\end{array}$ & $\begin{array}{l}\text { Sending guidance of Finding values in life, "do not dwell } \\
\text { on sleep problems and commit your life" }\end{array}$ \\
\hline
\end{tabular}

CBT-I, cognitive behavior therapy for insomnia; ACT, acceptance and commitment therapy 


\section{결 과}

\section{인구통계학적 특성}

본 연구는 연구 참여자들을 불면증 프로그램에 순차적으 로 배정된 두 개의 그룹으로 나누어 분석하였다. Group 1은 CBT-I에 배정된 집단이고, Group 2는 ACT를 기반으로 한 advanced CBT-I 집단이다. 성별은 Group 1에서 남성이 $66.7 \%$ 로 더 많았고, Group 2에서는 여성이 $60 \%$ 로 더 많았 다. Group 1의 평균 연령은 44.63세였고, Group 2의 평균 연 령은 43.50세였다. 교육수준은 Group 1이 고졸 학력이 50\%, 학사학위 취득이 $50 \%$ 였고, Group 2가 고졸이 $30 \%$, 학사학위 취득이 $70 \%$ 였다. Group 1과 Group 2에서 각각 50\%, 30\%의 참여자가 미혼이었고, $33.3 \%, 30 \%$ 의 참여자가 고용상태에 있었다. 그 외 카페인 섭취 및 알코올 섭취 정도도 두 군 간에 차이가 없었다(Table 2). 전체 피험자들의 $87.5 \%$ 이상이 중 등도 이상의 불면증이었고(ISI> 14 ), 두 그룹 간 불면증의 심

Table 2. Demographics of participants

\begin{tabular}{|c|c|c|c|c|}
\hline & $\begin{array}{c}\text { Group 1: } \\
\text { CBT-I } \\
(\mathrm{n}=6)\end{array}$ & $\begin{array}{c}\text { Group 2: } \\
\text { advanced } \\
\text { CBT-I }(n=10)\end{array}$ & $\mathrm{t}, \chi^{2}$ & $p$ \\
\hline Sex & & & 1.067 & 0.302 \\
\hline Female & $2(33.3)$ & $6(60)$ & & \\
\hline Male & $4(66.7)$ & $4(40)$ & & \\
\hline Age (yr) & $44.63 \pm 20.35$ & $43.50 \pm 16.05$ & 0.120 & 0.907 \\
\hline Education & & & 0.640 & 0.424 \\
\hline Under high school & 0 & 0 & & \\
\hline Undergraduate & $3(50)$ & $3(30)$ & & \\
\hline Bachelor's degree & $3(50)$ & $7(70)$ & & \\
\hline \multicolumn{5}{|l|}{ Marital status } \\
\hline Single & $3(50)$ & $3(30)$ & 1.067 & 0.587 \\
\hline Job status & & & 0.019 & 0.889 \\
\hline Employed & $2(33.3)$ & $3(30)$ & & \\
\hline Non-employed & $4(66.7)$ & $7(70)$ & & \\
\hline Caffeine (per day) & & & 1.905 & 0.386 \\
\hline Don't drink & $3(50)$ & $5(50)$ & & \\
\hline 1 or 2 cups & $2(33.3)$ & $5(50)$ & & \\
\hline 3 or more cups & $1(16.7)$ & 0 & & \\
\hline Alcoholic drink & & & 2.489 & 0.477 \\
\hline Don't drink & $3(50)$ & $6(60)$ & & \\
\hline $\begin{array}{l}\text { Once or twice a } \\
\text { month }\end{array}$ & $2(33.3)$ & $2(20)$ & & \\
\hline $\begin{array}{l}\text { Once or twice a } \\
\text { week }\end{array}$ & $1(16.7)$ & $2(20)$ & & \\
\hline
\end{tabular}

$\overline{\text { Data are presented as } \mathrm{n}(\%) \text { or mean } \pm \text { standard deviation. CBT-I, }}$ cognitive behavior therapy for insomnia
각도 차이는 없었다(Group 1, ISI, $18.0 \pm 1.8$ vs. Group 2, ISI, $18 \pm 7.0, p=0.767)$. 그 외 수면의 질, 우울, 불안, 수용 및 수면 에 대한 과도한 노력과 역기능적 생각, 주간 낮 졸림의 정도 모두 두 군 간에 차이가 없었다.

\section{불면증 증상의 변화 비교}

두 집단의 사전-사후 변화량에서의 차이를 살펴보기 위해 repeated measures ANOVA를 통해 불면증 증상 및 이차적 인 요소들의 변화 정도를 분석하였다(Fig. 1). CBT-I와 advanced CBT-I 프로그램을 마친 후 집단에 따른 불면증의 증상과 수면일기에서 집단에 따른 주효과와 상호작용 효과 는 유의하지 않아 두 프로그램의 효과 차이는 없는 것으로 나타났다. 이어서 시기에 따른 주효과에서는 불면증의 심각 도 $[\mathrm{F}(1,14)=29.127, p<0.001]$ 와 수면의 질 $[\mathrm{F}(1,14)=9.843$, $p=0.007]$ 이 유의하였다. 또한 수면일기로 측정한 수면효율 $[\mathrm{F}(1,14)=3.093, p=0.100]$ 과 수면 잠복기 $[\mathrm{F}(1,14)=4.380, p=$ $0.055]$ 를 제외한 총 수면시간[F(1,14)=8.111, $p=0.013], \mathrm{PSQI}$ 하위 요인 들 중 주관적인 수면의 질 $[\mathrm{F}(1,14)=7.626, p=0.015]$ 과 낮 동안의 기능장애 $[\mathrm{F}(1,14)=5.511, p=0.034]$ 에서 시기에 따른 주효과가 유의하였다. 이어서 불면증에 의한 우울, 불안 및 이차적인 증상에서 변화 정도를 분석하였을 때, 집단에 따 른 주효과와 상호작용 효과는 유의하지 않았다. 이어서 시기 에 따른 주효과에서는 내적 경험들에 대한 수용 $[\mathrm{F}(1,14)=9.888$, $p=0.008]$, 우울 $[\mathrm{F}(1,14)=11.229, p=0.005]$ 과 불안 $[\mathrm{F}(1,14)=$ $11.193, p=0.005]$, 수면에 대한 과도한 노력 $[\mathrm{F}(1,14)=25.562$, $p<0.001]$ 과 수면에 대한 역기능적 생각의 빈도 $[\mathrm{F}(1,14)=26.943$, $p<0.001]$ 가 유의하였다(Table 3). 두 집단의 순응도를 보았을 때, CBT-I 군에서는 75\%로 총 8명 중 2명인 47세 여성과 42 세 남성이 각각 2 회차, 3 회차에서 개인 일정상 병원 내원을 어려워하며 프로그램 참여를 중단하였고, advanced CBT-I 군에서는 $100 \%$ 로 중도 탈락은 없었으나 72 세 여성이 총 8 회 기를 다 마친 후 사후 설문에 참여하지 않았다.

\section{고 찰}

본 연구는 불면증 치료에 있어 전통적인 CBT-I의 행동요 법과 ACT의 요소를 가미한 advanced CBT-I의 효과를 검증 한 가설 설정(hypothesis generation)의 예비연구이다. CBT-I 와 advanced CBT-I는 불면증의 심각도와 같은 일차적인 증 상을 개선시키고, 수면에 대한 역기능적인 생각과 수면에 대 한 노력 및 우울과 불안 같은 이차적인 요소들을 완화시키는 데에도 효과를 보였다. 연구의 주요 결과와 의의를 구체적으 로 살펴보면 다음과 같다. 
PHQ-9

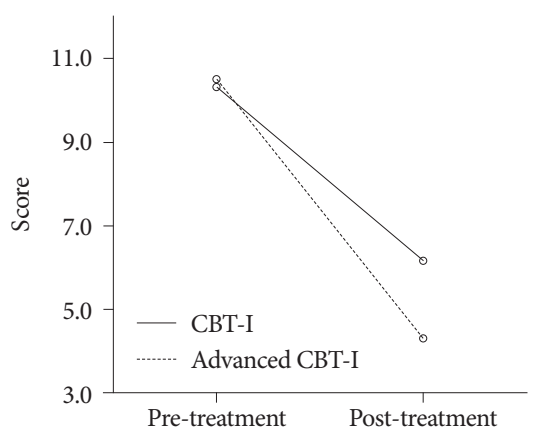

AAQ-II

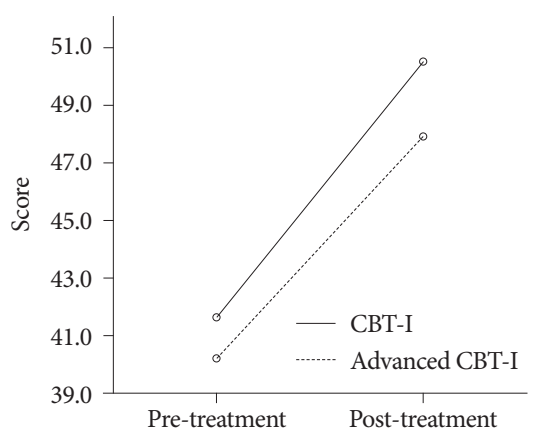

GAD-7

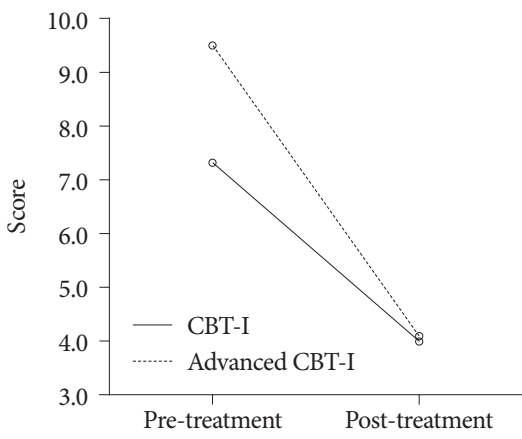

K-GSES

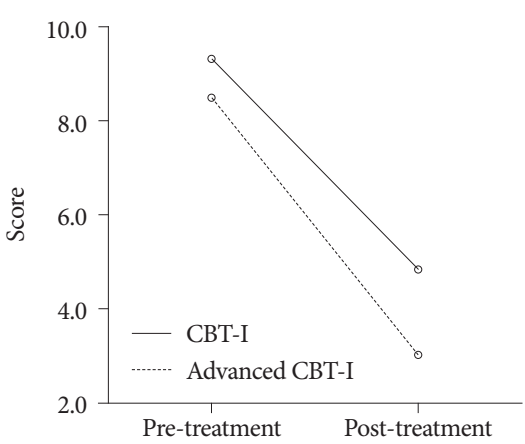

ESS
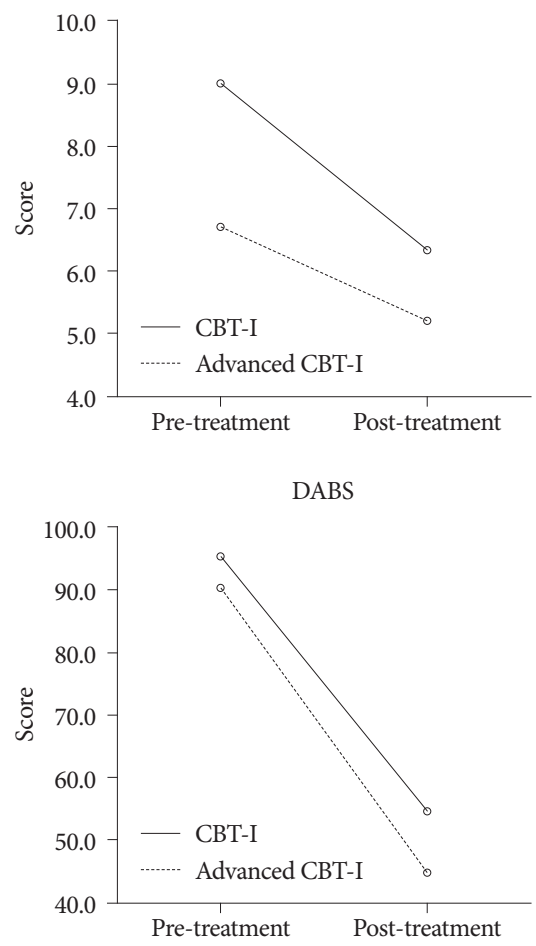

Figure 1. Secondary outcomes of advanced CBT-I compared with CBT-I: Values are shown as mean. PHQ-9, Patient Health Questionnaire-9; GAD-7, Generalized Anxiety Disorder-7; ESS, Epworth Sleepiness Scale; AAQ-II, Acceptance and Action Questionnaire-II; KGSES, Korean Glasgow Sleep Effort Scale; DABS, Dysfunctional Beliefs and Attitudes about Sleep scale.

첫째, CBT-I와 advanced CBT-I 모두에서 프로그램에 참여하기 전보다 참여자들의 수면에 대한 역기능적인 생각 과 노력 등 불면증의 심각도를 비롯한 불면증의 정도를 향 상시키는 효과가 있었으며, 효과의 정도에 차이가 거의 없어 CBT-I와 advanced CBT-I 모두 불면증에 효과가 있음을 나 타냈다. 본 연구에서 확인한 advanced CBT-I의 이러한 결 과는, $\mathrm{ACT}$ 가 만성 불면증 환자의 정서 조절장애와 수면의 질 향상에 효과를 보였다는 Khazaie와 Zakiei ${ }^{34}$ 의 연구와 $\mathrm{ACT}$ 를 이용한 불면증의 치료가 만성피로에 미치는 영향을 알아본 Kallestad 등 35 의 연구에서 불면증과 피로, 우울, 불안 의 수준이 모두 유의미하게 감소하였다는 결과 등 $\mathrm{ACT}$ 를 이용한 불면증의 치료 효과를 검증한 기존의 선행연구에서 확인한 불면증의 심각도와 수면의 질이 유의미하게 개선되 었다는 연구 결과와 일치한다. ${ }^{36-38}$ 또한, $\mathrm{CBT}-\mathrm{I}$ 와 $\mathrm{ACT}$ 를 기 반으로 하여 심리적 유연성을 향상시키기 위한 기법을 접목 시킨 프로그램의 효과를 비교한 El Rafihi-Ferreira 등 ${ }^{39}$ 의 연구와 ACT의 요소들을 접목시킨 CBI-I 프로그램의 효과 에 대한 Chapoutot 등 $^{40}$ 의 연구에서도 $\mathrm{ACT}$ 를 기반으로 한 프로그램이 CBT-I와 마찬가지로 불면증의 개선 효과를 보 였다는 결과와도 맥을 함께 한다.

둘째, 수면에 대한 생각의 융합이 강한 강박적인 성격 성 향의 환자에게 advanced CBT-I 프로그램의 인지적 탈융합
과정 또한 CBT-I의 인지요법과 마찬가지로 수면에 대한 역 기능적인 노력과 신념을 완화시키는 데 하나의 대안이 될 수 있는지 살펴보았다. 일반적으로 만성 불면증은 잠을 못 자는 것에 대한 생각과 걱정으로부터 시작되는데, 이러한 인지적 인 각성은 정서 및 신체적인 각성을 불러일으켜 수면시간을 줄어들게 하며 역기능적인 대처 전략을 하게 함으로써 불면 증의 악순환이 반복된다. 이러한 악순환은 환자가 잠을 자지 않는 것과 관련된 원치 않는 생각, 감정, 신체적 감각을 경험 하고 이를 피하는 과정에서 과각성을 유도하기 때문에 불면 증이 지속된다. 또한 최근 한 연구에서는 수면오지각 즉, 객 관적인 수면 지표에 비해 주관적으로 지각하는 수면 지표를 더 부정적으로 과대평가하여 불면증의 증상이 심한 환자들 에서 우울 정도 자체가 매개요인으로 작용하여 불면증의 심 각도를 더 높인다고 보고하였다. ${ }^{41}$ 따라서 수면장애를 경험할 때 $\mathrm{ACT}$ 를 통해 자연적으로 발생하는 생각들에 탈융합하고 경험들을 수용할 수 있도록 돕는 것은 불면증 환자에게 수면 에 대한 걱정과 이차적으로 심리적인 증상들을 낮추는 데에 도움이 될 것으로 보인다. 즉 환자가 불면증의 경험을 수용 하게 함으로써 각성이 낮아지면서 역설적으로 더 높은 수준 의 졸음을 경험할 수 있다. 이러한 과정에서 $\mathrm{ACT}$ 를 접목한 CBT-I는 기존 CBT-I의 인지수정 및 수면제한과 자극조절 에서 발생한 피로감 등의 단기적 불편감을 기꺼이 경험하게 
Table 3. Outcomes of advanced CBT-I compared with CBT-I

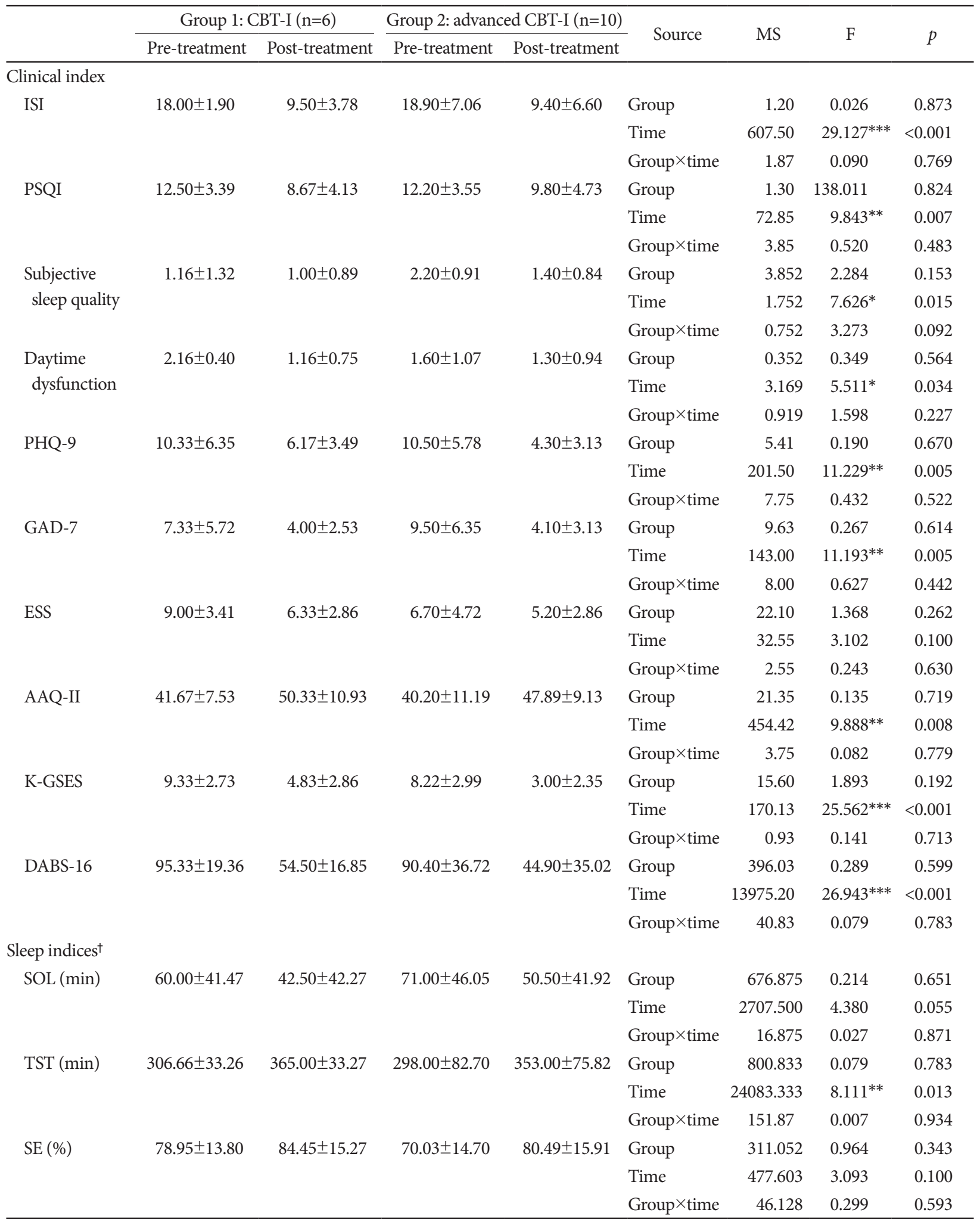

Data are presented as mean \pm standard deviation. ${ }^{*} p<0.05 ;{ }^{* *} p<0.01 ;{ }^{* * *} p<0.001 ;{ }^{\dagger}$ data analyzed by sleep diary. CBT-I, cognitive behavior therapy for insomnia; ISI, Insomnia Severity Index; MS, mean squares; PSQI, Pittsburgh Sleep Quality Index; PHQ-9, Patient Health Questionnaire-9; GAD-7, Generalized Anxiety Disorder-7; ESS, Epworth Sleepiness Scale; AAQ-II, Acceptance and Action Questionnaire-II; K-GSES, Korean Glasgow Sleep Effort Sale; DABS-16, Dysfunctional Beliefs and Attitudes about Sleep Scale-16; SOL, sleep onset latency; TST, total sleep time; SE, sleep efficiency 
하고, 역기능적인 신념을 변화시켜야 한다는 강박을 줄여주 는 것을 통해 불안을 낮춤으로써 장기적으로는 불면증의 인 지행동치료 효과를 잠재적으로 향상시킬 수 있겠다. ${ }^{42}$ 기존 의 선행연구에서는 정신질환을 가지고 있는 불면증 환자를 대상으로 acceptance and commitment therapy for insom$\operatorname{nia}(\mathrm{ACT}-\mathrm{I})$ 를 1 개월에 걸쳐 8 회기 동안 진행한 집단과 약물 치료 집단의 치료 효과를 분석한 Farhang 등 ${ }^{43}$ 의 연구에서 약물 치료 집단에 비해 ACT-I 집단에서 불면증의 개선효과 뿐 아니라 불안 수준도 유의하게 낮아졌다는 것을 확인한 바 있다. 이처럼 본 연구의 결과는, 우울과 불안 수준이 높아 수 면 위생에 대한 강박과 수면에 대한 인지적인 융합이 강한 강 박적인 성격 성향의 환자에게 $\mathrm{ACT}$ 를 기반으로 한 advanced CBT-I가 불안을 적절히 다루어 주어 치료의 중도 탈락을 방지하여 치료 회기를 마칠 수 있도록 도움을 줄 수 있음을 보여준다. 그러나 본 연구에서는 기존의 CBT-I에 비해 $\mathrm{ad}-$ vanced CBT-I에서 좀 더 개선될 것으로 생각하였던 우울, 불안 등에서 유의한 차이를 확인하지 못하였다. 이는 각 집 단의 사전 점수들에서 심한 정도의 우울과 불안의 환자 수 가 많지 않아 집단 간 심리적 완화의 효과 차이를 보기 어려 웠을 것으로 생각되며, 총 피험자 수가 적은 것 역시 두 그룹 간의 차이를 보지 못하였을 것으로 생각된다. 심리적 증상의 완화가 $\mathrm{ACT}$ 의 강점이 될 수 있는지 추후 좀 더 대규모 연구 에서 확인해 볼 필요가 있을 것이다.

셋째, advanced CBT-I에 접목되었던 ACT 요소들인 가치 의 명료화와 이에 따른 전념행동의 실천은 불면증 환자들에 게 증상의 몰입보다 일상의 가치를 찾아 나가는 데 도움이 될 수 있다는 점이다. 환자들은 스스로의 가치를 명료화하고 이 에 따른 전념행동들을 실천함으로써 증상에 매몰되는 시간이 감소되고 활력이 증가됨을 보고하였다. 전념행동은 $\mathrm{ACT}$ 의 핵심적인 요소로 명료화된 가치를 꾸준히 실천할 수 있게 하 며, 이는 불면증의 증상에 매몰되어 있는 환자들에게 증상과 는 별개로 삶의 가치와 이에 따른 행동의 실천이 가능하다는 것을 환기시킬 수 있다..$^{44}$ 이러한 관점을 획득하여 낮 동안에 보다 의미 있고 가치 있는 행동들을 실천하고 삶의 방향에 전 념하는 지속적인 경험을 통해 전반적인 수면의 질에 도움이 될 수 있다. 본 연구의 이와 같은 결과는 불면증의 치료 효과 뿐만 아니라 주관적인 삶의 질도 향상되었던 선행연구들과 같은 맥락이라 할 수 있다. ${ }^{20}$

본 연구의 제한점 및 후속연구를 위한 제언은 다음과 같다. 첫째, 본 연구는 총 16 명의 소규모 파일럿 연구로 가설 설정 및 입증의 연구이다. 이에 advanced CBT-I가 치료자와 치 료환경 및 치료 횟수의 동일한 조건하에 시행된 CBT-I와 마찬가지로 불면증 치료에 있어 효과를 가지는지 확인하였
다. 그러나 본 연구는 $\mathrm{N}$ 수가 적어 해석에 주의를 요해야 한 다. 향후 본 연구진은 예비 연구의 제한점들을 보완 진행하 여 CBT-I와 advanced CBT-I의 효과가 치료가 완료된 이 후에도 지속되는지, 지속된다면 어떠한 변인들에서 나타나 는지 등을 추수 회기 검사를 통해 확인해 볼 필요가 있다. 이를 통해 각 프로그램이 불면증의 요소들에 영향을 미치는 강점들을 살펴보고 불면증 환자에게 맞춤형 치료를 적용할 수 있을 것이다. 둘째, 연구 참여자들의 성별과 연령에 따른 집단 간 유의한 차이는 없었지만, 연구 참여의 중도 탈락결 과를 분석하였을 때 참여자의 기질적인 특성에 영향을 받 았을 수 있다. 또한 본 연구는 인지행동치료에 고령 환자도 포함하여 연령의 증가에 따른 인지기능 저하의 변인을 고려 하지 않았다. 고령 환자의 발달 단계로 인한 인지력 저하는 표준적인 치료적 개입에 적응하는 것에 문제가 될 수 있다 고 알려져 있고, ${ }^{45}$ 본 연구 참여자 중 중도탈락한 72 세 여성 은 설문지 작성에 어려움을 겪었으며 추후 Mini-Mental State Examination (MMSE) 검사에서 21점 이하의 인지기능 저하 가 확인되었다. 이에 인지행동치료에서 인지기능 저하가 결 과에 영향을 미칠 수 있음을 고려하지 않고 정형화된 스크 리닝 절차를 밟지 않은 것은 본 연구의 한계점이 될 수 있다. 추후 연구에서는 MMSE 등을 통한 스크리닝 절차를 거치고 인지기능 평가 및 더 나아가 성별과 연령 및 교육수준뿐만 아니라 참여자들의 다양한 변인들을 측정할 수 있는 척도들 을 추가하여 분석하는 것이 추후 개별화된 불면증의 인지행 동치료를 개발하는 데 도움이 될 것으로 보인다. 셋째, 본 연 구의 프로그램 참여 기간은 4주로 8회기를 진행하고 있으나, 불면증이 재발하지 않고 유지되기 위해서는 4주 이상의 프 로그램을 진행하여 증상의 호전을 살펴볼 필요가 있다. 더 나아가 본 연구에서는 부재했던 무처치군 통제집단을 설정 하여 향후 집단 간의 차이효과를 검증할 필요가 있겠다. 또 한 본 연구에서 측정한 척도들은 자기보고식 검사로서 객관 적인 수면시간 등을 측정하는 데 한계가 있다. 따라서 향후 연구에서는 자기보고식 검사의 한계를 보완할 수 있는 액티 워치와 같은 객관적 측정 도구들을 적용하여 불면증의 하위 요인의 변화 양상을 관찰할 필요가 있다. 넷째, 본 연구는 $\mathrm{ACT}$ 의 치료 변인들과 기존의 CBT-I의 행동요인들을 결합 하여 시도된 파일럿 연구로서 기존 CBT-I에서 중도탈락이 되는 경우를 보완할 수 있는 하나의 접근으로 시도되었다. 그러나 advanced CBT-I군에서도 CBT-I의 일부 행동요인 과 수면위생들의 기본적인 치료 변인들이 있어 두 군 모두 이로 인하여 불면증의 증상이 호전되었을 가능성이 있다. $\mathrm{ACT}$ 만의 정확한 효과를 보기 위해서는, 각 주차별 수면일기 를 통한 수면지표들의 호전도를 비교해 볼 수는 있겠다. 그 
러나 본 연구에서는 2,3 주차의 수면일기 자료들이 일부 누 락되어 각 주별로 두 군의 치료효과를 살펴보기 어렵다는 한 계점이 있다. 그럼에도 두 치료군의 프로그램은 1 주차부터 4 주차까지 각각 $\mathrm{CBT}$ 와 $\mathrm{ACT}$ 의 원리들이 불면증에 어떻게 적용되고 진행되는지 수면교육과 더불어 구조화 및 치료과정 등에서 지속적인 차이를 보이고 있고, 불면증을 위한 $\mathrm{ACT}$ 의 기존 선행연구 프로그램에서도 행동요인들에 있어 기준의 차이가 존재하여 프로그램의 차이를 보인다..$^{11}$ 따라서 $\mathrm{ACT}$ 의 치료 변인들로부터 기인한 효과 역시 존재했을 수도 있으 나, 보다 명확하게 살펴보기 위해서는 향후 CBT-I의 행동요 인들이 배제된 $\mathrm{ACT}$ 자체에서의 불면증 증상의 완화효과를 살펴볼 필요가 있다.

그럼에도 불구하고 본 연구의 의의를 살펴보면 다음과 같 다. 기존의 인지행동치료는 역기능적인 수면의 인지를 수정 하고 잘못된 수면의 습관을 변화시키는 데에 초점을 두었다 면 수용전념치료를 기반으로 한 인지행동치료에서는 변화보 다는 수용과 인지적 탈융합이라는 맥락을 도입한 예비연구 로 시도되었음에 의의를 둔다. 또한 불면증의 증상에 집중하 는 것이 아닌 삶의 가치를 명료화하고 이에 전념하는 행동활 성화를 통해 환자의 삶의 질을 향상시킬 수 있을 것이라 기 대한다.

\section{Conflicts of Interest}

The authors have no potential conflicts of interest to disclose.

\section{ORCID iDs}

Seonyeop Kim

Yoon Jung Shin

Bomi Park

Sunyoung Park

Jung-Won Shin https://orcid.org/0000-0001-7852-7900 https://orcid.org/0000-0003-3250-1363 https://orcid.org/0000-0001-9056-3437 https://orcid.org/0000-0002-3335-9330 https://orcid.org/0000-0003-2155-9068

\section{Author Contributions}

Conceptualization: Seonyeop Kim. Data curation: Seonyeop Kim, Yoon Jung Shin. Funding acquisition: Jung-Won Shin. Investigation: Yoon Jung Shin. Methodology: Seonyeop Kim, Sunyoung Park. Project administration: Jung-Won Shin. Supervision: Jung-Won Shin. Writing-original draft: Bomi Park, Yoon Jung Shin. Writing_-review \& editing: Bomi Park, JungWon Shin.

\section{Funding Statement}

This study was supported by the Research Grant of Korean Sleep Research Society in 2020 .

\section{REFERENCES}

1. Driscoll HC, Serody L, Patrick S, et al. Sleeping well, aging well: a descriptive and cross-sectional study of sleep in "successful agers" 75 and older. Am J Geriatr Psychiatry 2008;16:74-82. https://doi.org/10.1097/ JGP.0b013e3181557b69.

2. Li M, Zhang XW, Hou WS, Tang ZY. Insomnia and risk of cardiovascular disease: a meta-analysis of cohort studies. Int J Cardiol 2014;176: 1044-1047. https://doi.org/10.1016/j.ijcard.2014.07.284.
3. Kamel NS, Gammack JK. Insomnia in the elderly: cause, approach, and treatment. Am J Med 2006;119:463-469. https://doi.org/10.1016/ j.amjmed.2005.10.051.

4. Morin CM, Hauri PJ, Espie CA, Spielman AJ, Buysse DJ, Bootzin RR. Nonpharmacologic treatment of chronic insomnia. Sleep 1999;22:11341156. https://doi.org/10.1093/sleep/22.8.1134.

5. Harvey AG, Tang NK, Browning L. Cognitive approaches to insomnia. Clin Psychol Rev 2005;25:593-611. https://doi.org/10.1016/j.cpr.2005.04.005.

6. Spielman AJ, Caruso LS, Glovinsky PB. A behavioral perspective on insomnia treatment. Psychiatr Clin North Am 1987;10:541-553.

7. Jacobs GD, Pace-Schott EF, Stickgold R, Otto MW. Cognitive behavior therapy and pharmacotherapy for insomnia: a randomized controlled trial and direct comparison. Arch Intern Med 2004;164:1888-1896. https://doi.org/10.1001/archinte.164.17.1888.

8. Mitchell MD, Gehrman P, Perlis M, Umscheid CA. Comparative effectiveness of cognitive behavioral therapy for insomnia: a systematic review. BMC Fam Pract 2012;13:40. https://doi.org/10.1186/1471-2296-13-40.

9. Castronovo V, Galbiati A, Sforza M, et al. Long-term clinical effect of group cognitive behavioral therapy for insomnia: a case series study. Sleep Med 2018;47:54-59. https://doi.org/10.1016/j.sleep.2018.03.017.

10. Ong JC, Kuo TF, Manber R. Who is at risk for dropout from group cognitive-behavior therapy for insomnia? J Psychosom Res 2008;64:419425. https://doi.org/10.1016/j.jpsychores.2007.10.009.

11. Cui R, Fiske A. Predictors of treatment attendance and adherence to treatment recommendations among individuals receiving cognitive behavioral therapy for insomnia. Cogn Behav Ther 2020;49:113-119. https://doi.org/10.1080/16506073.2019.1586992.

12. Spielman AJ, Saskin P, Thorpy MJ. Treatment of chronic insomnia by restriction of time in bed. Sleep 1987;10:45-56.

13. Broomfield NM, Espie CA. Towards a valid, reliable measure of sleep effort. J Sleep Res 2005;14:401-407. https://doi.org/10.1111/j.13652869.2005.00481.x.

14. Heidenreich T, Tuin I, Pflug B, Michal M, Michalak J. Mindfulnessbased cognitive therapy for persistent insomnia: a pilot study. Psychother Psychosom 2006;75:188-189. https://doi.org/10.1159/000091778.

15. Hayes SC, Luoma JB, Bond FW, Masuda A, Lillis J. Acceptance and commitment therapy: model, processes and outcomes. Behav Res Ther 2006;44:1-25. https://doi.org/10.1016/j.brat.2005.06.006.

16. Ong JC, Ulmer CS, Manber R. Improving sleep with mindfulness and acceptance: a metacognitive model of insomnia. Behav Res Ther 2012; 50:651-660. https://doi.org/10.1016/j.brat.2012.08.001.

17. Dalrymple KL, Fiorentino L, Politi MC, Posner D. Incorporating principles from acceptance and commitment therapy into cognitive-behavioral therapy for insomnia: a case example. J Contemp Psychother 2010;40:209-217. https://doi.org/10.1007/s10879-010-9145-1.

18. Salari N, Khazaie H, Hosseinian-Far A, et al. The effect of acceptance and commitment therapy on insomnia and sleep quality: a systematic review. BMC Neurol 2020;20:300. https://doi.org/10.1186/s12883-02001883-1.

19. Zakiei A, Khazaie H. The effectiveness of acceptance and commitment therapy on insomnia patients (a single-arm trial plan). J Turk Sleep Med 2019;6:65-73. https://doi.org/10.4274/jtsm.galenos.2019.74745.

20. Lappalainen P, Langrial S, Oinas-Kukkonen H, Muotka J, Lappalainen R. ACT for sleep-internet-delivered self-help ACT for sub-clinical and clinical insomnia: a randomized controlled trial. J Contextual Behav Sci 2019;12:119-127. https://doi.org/10.1016/j.jcbs.2019.04.001.

21. Sateia MJ. International classification of sleep disorders-third edition: highlights and modifications. Chest 2014;146:1387-1394. https://oi. org/10.1378/chest.14-0970.

22. Buysse DJ, Reynolds CF 3rd, Monk TH, Berman SR, Kupfer DJ. The Pittsburgh sleep quality index: a new instrument for psychiatric practice and research. Psychiatry Res 1989;28:193-213. https://doi.org/10.1016/ 0165-1781(89)90047-4.

23. Cho YW, Song ML, Morin CM. Validation of a Korean version of the insomnia severity index. J Clin Neurol 2014;10:210-215. https://doi. 
org/10.3988/jcn.2014.10.3.210.

24. Morin CM, Belleville G, Bélanger L, Ivers $H$. The insomnia severity index: psychometric indicators to detect insomnia cases and evaluate treatment response. Sleep 2011;34:601-608. https://doi.org/10.1093/ sleep/34.5.601.

25. Johns MW. Reliability and factor analysis of the Epworth Sleepiness Scale. Sleep 1992;15:376-381. https://doi.org/10.1093/sleep/15.4.376.

26. Han C, Jo SA, Kwak JH, et al. Validation of the patient health questionnaire-9 Korean version in the elderly population: the Ansan geriatric study. Compr Psychiatry 2018;49:218-223. https://doi.org/10.1016/j. comppsych.2007.08.006.

27. Spitzer RL, Kroenke K, Williams JB, Löwe B. A brief measure for assessing generalized anxiety disorder: the GAD-7. Arch Intern Med 2006;166:1092-1097. https://doi.org/10.1001/archinte.166.10.1092.

28. Heo JH, Choi MS, Jin HJ. Study on the reliability and validity of Korean translated acceptance-action questionnaire-2. Korean J Counseling and Psychotherapy 2009;21:861-878.

29. Kim MK, Koo HJ, Kwon JH, Han JG. Validation of Korean version of Glasgow sleep effort scale (GSES). Cognitive Behavior Therapy in Korea 2014;14:319-337.

30. Yu ES, Ko YG, Sung GH, Kwon JH. Validation of the Korean version of dysfunctional beliefs and attitudes about sleep (K-DBAS-16). Kor J Clin Psychol 2009;28:309-320. https://doi.org/10.15842/kjcp.2009.28.1.018.

31. Meadows G. Acceptance and commitment therapy for insomnia (ACTI) [Internet]. Jenison, MI: Association for Contextual Behavioral Science; 2020 [cited 2021 Mar 13]. Available from: https://contextualscience.org/ acceptance_and_commitment_therapy_for_insomnia_act.

32. Zakiei A, Khazaie H, Rostampour M, et al. Acceptance and commitment therapy (ACT) improves sleep quality, experiential avoidance, and emotion regulation in individuals with insomnia-results from a randomized interventional study. Life (Basel) 2021;11:133. https://doi. org/10.3390/life11020133.

33. Hertenstein E, Thiel N, Lüking M, et al. Quality of life improvements after acceptance and commitment therapy in nonresponders to cognitive behavioral therapy for primary insomnia. Psychother Psychosom 2014:83:371-373. https://doi.org/10.1159/000365173.

34. Khazaie H, Zakiei A. Efficacy of acceptance and commitment therapy on emotional dysregulation and sleep quality in patients with chronic insomnia. J Mazandaran Univ Med Sci 2019;29:52-63.

35. Kallestad H, Jacobsen HB, Landrø NI, Borchgrevink PC, Stiles TC. The role of insomnia in the treatment of chronic fatigue. J Psychosom
Res 2015;78:427-432. https://doi.org/10.1016/j.jpsychores.2014.11.022.

36. Craner JR, Lake ES, Bancroft KA, George LL. Treatment outcomes and mechanisms for an ACT-based 10-week interdisciplinary chronic pain rehabilitation program. Pain Pract 2020;20:44-54. https://doi. org/10.1111/papr.12824.

37. Jacobsen HB, Kallestad H, Landrø NI, Borchgrevink PC, Stiles TC. Processes in acceptance and commitment therapy and the rehabilitation of chronic fatigue. Scand J Psychol 2017;58:211-220. https://doi. org/10.1111/sjop.12363.

38. Lang AJ, Schnurr PP, Jain S, et al. Randomized controlled trial of acceptance and commitment therapy for distress and impairment in OEF/OIF/OND veterans. Psychol Trauma 2017;9:74-84. https://doi. org/10.1037/tra0000127.

39. El Rafihi-Ferreira R, Morin CM, Toscanini AC, et al. Acceptance and commitment therapy-based behavioral intervention for insomnia: a pilot randomized controlled trial. Braz J Psychiatry 2020 Dec 18 [Epub]. https://doi.org/10.1590/1516-4446-2020-0947.

40. Chapoutot M, Peter-Derex L, Schoendorff B, Faivre T, Bastuji H, Putois B. Telehealth-delivered CBT-I programme enhanced by acceptance and commitment therapy for insomnia and hypnotic dependence: a pilot randomized controlled trial. J Sleep Res 2020;30:e13199. https:// doi.org/10.1111/jsr.13199.

41. Lee J, Joo EY, Choi SJ, Suh S. The mediating effect of depression in the relationship between sleep misperception and insomnia severity among insomnia patients. J Sleep Med 2020;17:159-166. https://doi.org/10.13078/ jsm.200029.

42. Swain J, Hancock K, Hainsworth C, Bowman J. Acceptance and commitment therapy in the treatment of anxiety: a systematic review. Clin Psychol Rev 2013;33:965-978. https://doi.org/10.1016/j.cpr.2013.07.002.

43. Farhang M, Ghaderi M, Soleimani R, Arabshahi F. The effectiveness of acceptance and commitment group therapy in general health, happiness, and general well-being among mental disorder patients. Saussurea 2017;6:99-117.

44. Lin J, Scott W, Carpenter L, et al. Acceptance and commitment therapy for chronic pain: protocol of a systematic review and individual participant data meta-analysis. Syst Rev 2019;8:140. https://doi.org/10.1186/ s13643-019-1044-2.

45. Bélanger L, LeBlanc M, Morin CM. Cognitive behavioral therapy for insomnia in older adults. Cogn Behav Pract 2012;19:101-115. https:// doi.org/10.1016/j.cbpra.2010.10.003. 